\title{
ФАЗОМОДУЛЬОВАНЕ ПАРАМЕТРИЧНЕ АНТИСТОКСОВЕ ВИМУШЕНЕ КОМБІНАЦІЙНЕ РОЗСІЯННЯ ЧЕРЕНКОВСЬКОГО ТИПУ В ОБЛАСТЯХ САМОФОКУСУВАННЯ ЗБУДЖУЮЧОГО ВИПРОМІНЮВАННЯ
}

\author{
A.I. IBAHICIK, ${ }^{1}$ O.Ю. ICAЄHKO,${ }^{1}$ П.А. КОРОТКОВ,${ }^{1}$ Г.В. ПОНЕЖА ${ }^{2}$ \\ ${ }^{1}$ Київський національний університет ім. Тараса Шевченка, \\ радіофізичний факультет \\ (Просп. Академіка Глушкова, 2, корп. 42, Kü̈ 03127; e-mail: aivan@univ. kiev. ua) \\ ${ }^{2}$ Національна академія статистики, обліку та аудиту \\ (Вул. Підгірна, 1, Київ 04107)
}

\begin{abstract}
Розглянуто вплив швидкості руху фокальної точки самофокусування та фазової самомодуляції на частотно-кутові спектри випромінювання параметричної антистоксової компоненти вимушеного комбінаційного розсіяння. Враховано фазову самомодуляцію як збуджуючого, так і розсіяного антистоксового випромінювання. Пояснено утворення протяжних антистоксових частотно-кутових смуг. У випадку збігання швидкості фокальної точки самофокусування з фазовою швидкістю нелінійної поляризації на антистоксовій комбінаційній частоті та фазовою швидкістю розсіяного осьового випромінювання утворюються найінтенсивніші частотно-кутові смуги, які описуються співвідношеннями, характерними для черенковського випромінювання. Зокрема, за збудження наносекундними лазерними імпульсами в толуолі такі смуги сягають довжини $\approx-200 \mathrm{~cm}^{-1}$ відносно комбінаційної антистоксової частоти.
\end{abstract}

\section{1. Вступ}

У багатьох середовищах, в яких суттєвим є ефект Керра, самофокусування (СФ) випромінювання лазерних імпульсів у діапазоні наносекундної тривалості внаслідок зміни миттєвої потужності імпульсів приводить до переміщення фокальної плями. Швидкість $v_{\mathrm{fp}}$ фокальної плями визначається формою огинаючої лазерного імпульсу. Чим швидше змінюється миттєва потужність імпульсу, тим більшою може бути швидкість $v_{\mathrm{fp}}$. На фронті та спаді імпульсу $v_{\mathrm{fp}}$ набуває як додатних, так і від'ємних значень та не обмежена швидкістю світла у вакуумі.

У роботі [1] зазначалося, що рух фокальної плями $з$ надсвітловою швидкістю не суперечить спеціальній теорії відносності, оскільки фокальна пляма в різні моменти часу утворюється внаслідок СФ різних часових фрагментів вхідного імпульсу. Тож рух фокальної плями не пов'язаний з перенесенням енергії.
Проте з'являється сильна поляризація середовища, наведена в рухомому фокусі, яка може мати надсвітлову швидкість. Виникає ситуація, аналогічна тій, за якої спостерігається випромінювання ВавіловаЧеренкова.

За СФ породжуються в практичному і теоретичному аспекті нові обставини, які неможливо або важко створити в інших умовах та іншими технічними засобами.

Так, на відміну від використання звичайних лінз довжина $b$ фокальної області змінюється від $\sim 0,1$ до 10 мм за її радіуса $\sim 5$ мкм. Тривалість дії самофокусованого лазерного випромінювання у фіксованій точці середовища становить $\sim b / v_{\text {fp }}$. Коли швидкість фокальної точки є надсвітловою, то за мінімальної довжини $b$ тривалість дії $b / v_{\mathrm{fp}}$ зменшується до фемтосекундного діапазону навіть для наносекундних збуджуючих лазерних імпульсів.

Без СФ групова швидкість нелінійної поляризації і групова швидкість збуджуючого лазерного імпульсу практично збігаються. За СФ нелінійні оптичні процеси, зокрема вимушене комбінаційне розсіяння світла (BKP), вимушене розсіювання світла Мандельштама-Бріллюена, генерація оптичних гармонік тощо, відбуваються в умовах, коли швидкість огинаючої амплітуди нелінійної поляризації є близькою до $v_{\mathrm{fp}}$ та не залежить від групових швидкостей збуджуючих і генерованих компонент. Швидкість $v_{\mathrm{fp}}$ фокальної точки СФ є змінною та, в принципі, контрольованою, внаслідок залежності від форми огинаючої та амплітуди збуджуючого імпульсу.

Без СФ ефективність нелінійних оптичних процесів є максимальною за рівності усіх фазових і, як наслідок, групових швидкостей взаємодіючих та утворених хвиль, що не завжди реалізується. За СФ навіть 
у дисперсному середовищі ефективність нелінійних оптичних процесів завдяки перспективам нових технологій є принципово керованою та може бути оптимізована за рахунок вибору $v_{\mathrm{fp}}$.

Проте на ефективність нелінійних оптичних процесів в умовах СФ суттєво впливає фазова самомодуляція (ФС) лазерного випромінювання, яка змінює частоту та фазову узгодженість взаємодіючих хвиль.

У роботі проаналізовано вплив руху фокальної області СФ на параметричне антистоксове ВКР з урахуванням ФС лазерного випромінювання і випромінювання антистоксової компоненти (AK), яка утворюється в околі фокальної точки [2] та поширюється до межі середовища (до спостерігача) за змінного в часі та просторі показника заломлення.

Раніше було показано [3], що частота AK у BKPактивних середовищах залежить від швидкості фокальної точки навіть у наближенні "ідеальної тонкої лінзи", коли зміна миттєвої потужності лазерного імпульсу приводить лише до зміни фокусної відстані наведеної лінзи, а ФС є неістотною. Таку ситуацію принципово нескладно реалізувати, змінюючи радіуси кривизни додаткової лінзи за відсутності СФ. Проте реальна наведена лінза в СФ-середовищі змінює свою "товщину", що приводить до значної ФС лазерного випромінювання та АK.

Теоретично та експериментально спектр випромінювання самомодульованих лазерних імпульсів наносекундного діапазону тривалості є дослідженим [4]. За перетину фокальною точкою вихідної межі СФсередовища на фронті лазерного імпульсу спектральні розширення лазерного випромінювання перевищують $100 \mathrm{~cm}^{-1}$ у бік зменшення частоти. Це пояснено перехідним ефектом на межі СФ-середовища, який має деякі аналогії з фізичним механізмом утворення перехідного випромінювання [5]. У момент перетину межі керрівського середовища фокальною областю, в якій показник заломлення збільшений та змінний у часі, змінюються фази електромагнітних полів. Перехідний ефект за СФ може використовуватися для перебудови частоти та компресії лазерних імпульсів [6].

Спектральні розширення лазерного випромінювання внаслідок ФС у ВКР-активних самофокусуючих середовищах у подальшому приводять до розширення спектрів ВКР, яке відбувається у фокальних областях СФ [2], тобто в околі фокальної точки.

Експериментально встановлено [7], що в частотнокутових спектрах конусного випромінювання АK BKP спостерігаються частотно $(\omega)$ - кутові $(\theta)$ смуги $\omega(\theta)$ різної спектральної протяжності. Найхарактер- нішими в залежності частоти $\omega$ розсіяного випромінювання від кута $\theta \in$ параболоподібні частотно-кутові смуги $\omega(\theta)-\omega_{\mathrm{a}} \approx\left(\omega(\theta=0)-\omega_{\mathrm{a}}\right)\left(1-\theta^{2} / \theta^{2}\left(\omega_{\mathrm{a}}\right)\right)$, де $\omega_{\mathrm{a}}-$ комбінаційна антистоксова частота, а кут $\theta$ відраховується між віссю поширення лазерного імпульсу і напрямком розсіяного конусного випромінювання AK (кут $\theta=0$ відповідає осьовому розсіюванню).

Стоксовий зсув у вказаних смугах описується умовою, подібною до умови черенковського випромінювання [7]: $\cos \theta(\omega)=v_{\text {ph }}(\omega) / v_{\text {ap } 0}\left(\omega_{\mathrm{a}}\right)$, де $v_{\text {ph }}(\omega)$ - фазова швидкість розсіяного AK-випромінювання на частоті $\omega$ під кутом $\theta, v_{\text {ар0 }}\left(\omega_{\mathrm{a}}\right)$ - фазова швидкість хвилі нелінійної поляризації середовища на частоті $\omega_{\mathrm{a}}$ за відсутності СФ. В умовах нормальної дисперсії швидкість $v_{\text {ар0 }}\left(\omega_{\mathrm{a}}\right)$ є надсвітловою. Для частоти $\omega=\omega_{\mathrm{a}}$ маємо $\cos \theta=k_{\text {ap0 }}\left(\omega_{\mathrm{a}}\right) / k\left(\omega_{\mathrm{a}}\right)$, де $k_{\text {ap0 }}$ і $k$ - модулі хвильових векторів поляризації та хвилі у середовищі. На таку залежність черенковського типу на комбінаційній антистоксовій частоті $\omega_{\mathrm{a}}$ увага зверталася раніше [8]. Подібні залежності спостерігаються і за збудження фемтосекундними лазерними імпульсами, зокрема, сфокусованими за допомогою аксикона [9].

Непоясненим залишився фізичний механізм утворення некомбінаційних частот конусного випромінювання AK черенковського типу та їх зв'язок зі швидкістю фокальної точки і ФС лазерного випромінювання. В роботі [7] лише з формальної точки зору показано, що частотно-кутовий спектр експериментально спостережуваного широкосмугового конусного випромінювання AK аналітично може бути задовільно описаний умовою черенковського випромінювання $\cos \theta(\omega)=v_{\mathrm{ph}}(\omega) / v_{\text {ар0 }}\left(\omega_{\mathrm{a}}\right)$, в якій замість швидкості зарядженої частинки фігурує фазова швидкість $v_{\text {ар0 }}\left(\omega_{\mathrm{a}}\right)$ хвилі нелінійної поляризації середовища на частоті $\omega_{\mathrm{a}}$ за відсутності СФ і ФС.

Метою цієї роботи є з'ясування та аналітичний опис фізичного механізму, що зумовлює формування широкосмугового, залежного від кута, AK-випромінювання черенковського типу у BKPактивних СФ-середовищах з урахуванням ФС як збуджуючого, так і розсіяного антистоксового випромінювання.

Актуальність роботи визначається практично неврахованими можливостями, які реалізуються за поєднання ВКР як ефективного методу перебудови частоти лазерного випромінювання, та СФ, що забезпечує просторове сканування згустками електромагнітного поля із необмеженою та заданою швидкістю. Швидкість $v_{\mathrm{fp}}$ фокальної точки СФ не залежить безпосередньо від групової швидкості збуджуючого імпульсу та швидкості світла у вакуумі [1]. Це відкри- 
ває перспективи для створення нових джерел когерентного випромінювання з перебудовою частоти та новими частотно-кутовими характеристиками. Одночасно з'являється можливість свіпування лазерного випромінювання на зміщеній частоті.

\section{2. Аналітичний розгляд}

Джерелом випромінювання АK ВKP є хвиля $P^{\mathrm{NL}}(t, r)$ нелінійної поляризації середовища. Інтенсивність АK залежить як від просторово-часового розподілу амплітуди, так і фази цієї хвилі, оскільки необхідним є фазове узгодження з полем антистоксового випромінювання. За однакової поляризації всіх хвиль, в електродипольному наближенні для випадку однорідного немагнітного і непровідного середовища, без урахування відбиття на межах середовища частотно-кутова густина енергії $W_{\omega \theta}$ AK у дальньому полі для невеликих кутів розсіяння $\theta$ (у межах декількох градусів) визначається за формулою [3]:

$$
W_{\omega \theta}=\frac{\omega^{4} n_{\omega}}{8 \pi^{2} c^{3}}\left|\int_{V} d V \int_{-\infty}^{\infty} P^{\mathrm{NL}}(t, \mathbf{r}) \exp [i(\omega t-\mathbf{k r})] d t\right|^{2}
$$

де $\mathbf{k}$ - хвильовий вектор розсіяного випромінювання 3 модулем $k=n \omega / c$ на частоті $\omega, n=n(\omega)-$ показник заломлення, $c$ - швидкість світла у вакуумі, $t$ - час, $\mathbf{r}$ - радіус-вектор, який сполучає початок системи координат з довільною точкою об'єму $V$, де існує нелінійна поляризація середовища. Фізичний зміст формули (1) полягає у розкладанні нелінійної поляризації в кожній точці простору на неперервну за частотою сукупність монохроматичних точкових джерел випромінювання $з$ подальшим підсумовуванням поля випромінювання від цих джерел за просторовими координатами з урахуванням фази самих джерел і поля випромінювання, яке надходить у точку спостереження.

Для виконання розрахунків частотно-кутової густини енергії за формулою (1), необхідно спочатку визначити лише просторово-часову залежність амплітуди і фази поляризації $P^{\mathrm{NL}}(t, \mathbf{r})$. Проте в умовах СФ і ФС це є дуже складною задачею.

Для спрощення розрахунків використовуватимемо наближення заданої поляризації. Вважатимемо, що за нехтування СФ і ФС лінійно поляризоване збуджуюче лазерне випромінювання з хвильовим вектором $\mathbf{k}_{\mathrm{L}}$ (у середовищі) і частотою $\omega_{\mathrm{L}}$ поширюється вздовж осі $\mathbf{z}$ та має фазу $\phi_{\mathrm{L}}=\omega_{\mathrm{L}} t-k_{\mathrm{L}} z$. У тому самому напрямі поширюється і збуджена лазером стоксова комбінаційна компонента ВКР із хвильовим вектором $\mathbf{k}_{\mathrm{s}}$ та частотою $\omega_{\mathrm{s}}$. Ці дві хвилі породжують кубічну поляризацію середовища на антистоксовій комбінаційній частоті $\omega_{\mathrm{a}}=2 \omega_{\mathrm{L}}-\omega_{\mathrm{s}}$ із хвильовим вектором $\mathbf{k}_{\mathrm{ap0}}=2 \mathbf{k}_{\mathrm{L}}-\mathbf{k}_{\mathrm{s}}$. Оскільки $\mathbf{k}_{\mathrm{L}} \mathrm{i} \mathbf{k}_{\mathrm{s}}$ мають однаковий напрямок, то вектор $\mathbf{k}_{\text {ар0 }}$ теж спрямований уздовж осі $z$ і його модуль $k_{\text {ap0 }}=2 k_{\mathrm{L}}-k_{\mathrm{s}}$.

У випадку СФ внаслідок збільшення показника заломлення $\Delta n$ модуль $k_{\mathrm{L}}$ зростає на величину $\Delta k_{\mathrm{L}}=$ $k_{\mathrm{L}} \Delta n / n$ і створюється фазова затримка $\delta \varphi_{\mathrm{L}}(t, z)$ лазерного випромінювання. Тому маємо $\varphi_{\mathrm{L}}=\omega_{\mathrm{L}} t-$ $k_{\mathrm{L}} z-\delta \varphi_{\mathrm{L}}(t, z)$. Затримка залежить від миттєвої інтенсивності збуджуючих імпульсів випромінювання та відстані, а отже, часу $t$ i координати $z$, та визначається за виразом

$\delta \varphi_{\mathrm{L}}(t, z)=\int_{Z_{\mathrm{in}}}^{z} \Delta k_{\mathrm{L}}(t, \zeta) d \zeta$

У (2) прийнято, що ВКР-активне самофокусуюче середовище, розташоване в межах $z=Z_{\text {in }}-L / 2$ (надалі, координата $z_{\mathrm{f}}$ утвореної фокальної точки розглядається в інтервалі $z_{\mathrm{f}}=-L / 2-L / 2$ і $\left.Z_{\text {in }} \ll-L / 2\right)$, $\zeta$ - поточна координата інтегрування на шляху між вхідною межею середовища і точкою $z$, в якій розглядається фаза. Затримку $\delta \varphi_{\mathrm{L}}$ можна розрахувати достатньо точно, що і було зроблено в [4]. У даному випадку для приросту $\Delta k_{\mathrm{L}}(t, \zeta)$ модуля хвильового вектора лазерного випромінювання внаслідок збільшення показника заломлення в кожній проміжній точці $\zeta$ на шляху $Z_{\text {in }}-z$ використаємо наближення

$\Delta k_{\mathrm{L}}(t, \zeta)=\Gamma_{\mathrm{f}} \exp \left[-\left(\zeta-v_{\mathrm{fp}}\left(t-\frac{z-\zeta}{v_{\mathrm{g}}}\right)\right)^{2} / b^{2}\right]$

де $\Gamma_{\mathrm{f}}$ - максимальний приріст $\Delta k_{\mathrm{L}}$ в центрі фокальної області (у фокальній точці), $v_{\mathrm{fp}}$ - швидкість фокальної точки 3 координатою $z_{\mathrm{f}}=v_{\mathrm{fp}} t$ (припускаємо, що швидкість є сталою і $\left.z_{\mathrm{f}}(t=0)=0\right), v_{\mathrm{g}}-$ групова швидкість світла на частоті лазерного випромінювання, $b$ - ефективна довжина фокальної області. Вираз (3) відображає ту ситуацію, що деякий часовий фрагмент лазерного імпульсу, який в момент $t$ перебуває в точці $z$, був у точці $\zeta$ в момент $t^{\prime}=t-(z-\zeta) / v_{\mathrm{g}}$. В цей момент координата фокальної точки становила $z_{\mathrm{f}}^{\prime}=v_{\mathrm{fp}} t^{\prime}=v_{\mathrm{fp}}\left(t-(z-\zeta) / v_{\mathrm{g}}\right)$. Відповідно відстань між фрагментом і фокальною то- 
чкою була $\zeta-z_{\mathrm{f}}^{\prime}=\zeta-v_{\mathrm{fp}}\left(t-(z-\zeta) / v_{\mathrm{g}}\right)$. Це при гаусовому розподілі показника заломлення в фокальній області, пропорційному $\exp \left[-\left(\left(z-z_{\mathrm{f}}\right) / b\right)^{2}\right]$, дає шуканий вираз (3) для $\Delta k_{\mathrm{L}}(t, \zeta)$.

Фокальна область утворюється поблизу вихідної межі середовища. За умови $L / 2 \gg\left|Z_{\text {in }}\right|, b$ поблизу вхідної межі $\Delta k_{\mathrm{L}}(t, \zeta) \approx 0$. Отже, в $(2)$ нижню межу інтегрування можна замінити на $-\infty$.

ВКР переважно відбувається у центрі фокальної області СФ. Тому важливою є поведінка фази збуджуючого лазерного випромінювання саме в фокальній точці. Для фокальної точки підстановка $z=v_{\mathrm{fp}} t$ або $t=z / v_{\text {fp }}$ у $(2),(3)$ дає

$\delta \varphi_{\mathrm{L}}\left(t, z=v_{\mathrm{fp}} t\right)=\frac{\sqrt{\pi}}{2} b \Gamma_{\mathrm{f}}\left|\frac{1}{1-v_{\mathrm{fp}} / v_{\mathrm{g}}}\right|$

$\left.\frac{\partial \delta \varphi_{\mathrm{L}}}{\partial t}\right|_{z=v_{\mathrm{fp}} t}=-\Gamma_{\mathrm{f}} \frac{v_{\mathrm{fp}}}{1-v_{\mathrm{fp}} / v_{\mathrm{g}}}$

$\left.\frac{\partial \delta \varphi_{\mathrm{L}}}{\partial z}\right|_{z=v_{\mathrm{fp}} t}=\Gamma_{\mathrm{f}} \frac{1}{1-v_{\mathrm{fp}} / v_{\mathrm{g}}}$.

Отже, з урахуванням СФ і ФС у фокальній точці частота $\omega_{\mathrm{Lf}}$ та модуль $k_{\mathrm{Lf}}$ хвильового вектора лазерного випромінювання змінюються і становлять:

$\omega_{\mathrm{Lf}}=\left.\frac{\partial\left(\varphi_{\mathrm{L}}\right)}{\partial t}\right|_{z=v_{\mathrm{fp}} t}=\omega_{\mathrm{L}}+\Gamma_{\mathrm{f}} \frac{v_{\mathrm{fp}}}{1-v_{\mathrm{fp}} / v_{\mathrm{g}}}$,

$k_{\mathrm{Lf}}=-\left.\frac{\partial\left(\varphi_{\mathrm{L}}\right)}{\partial z}\right|_{z=v_{\mathrm{fp}} t}=k_{\mathrm{L}}+\Gamma_{\mathrm{f}} \frac{1}{1-v_{\mathrm{fp}} / v_{\mathrm{g}}}$.

В околі фокальної точки, використовуючи перші похідні і лінійну апроксимацію, для фазової затримки маємо

$\delta \varphi_{\mathrm{L}}(t, z)=\delta \varphi_{\mathrm{L}}\left(t, z_{\mathrm{f}}=v_{\mathrm{fp}} t\right)+$

$+\left.\frac{\partial \delta \varphi_{\mathrm{L}}}{\partial t}\right|_{z=v_{\mathrm{fp}} t}\left(t-z_{\mathrm{f}} / v_{\mathrm{fp}}\right)+\left.\frac{\partial\left(\varphi_{\mathrm{L}}\right)}{\partial z}\right|_{z=v_{\mathrm{fp}} t}\left(z-z_{\mathrm{f}}\right)=$

$=\frac{\sqrt{\pi}}{2} b \Gamma_{\mathrm{f}}\left|\frac{1}{1-v_{\mathrm{fp}} / v_{\mathrm{g}}}\right|-\Gamma_{\mathrm{f}} \frac{v_{\mathrm{fp}}}{1-v_{\mathrm{fp}} / v_{\mathrm{g}}} t+\Gamma_{\mathrm{f}} \frac{1}{1-v_{\mathrm{fp}} / v_{\mathrm{g}}} z$.

Фазова самомодуляція лазерного випромінювання переноситься на фазу $\varphi_{\mathrm{s}}$ стоксової компоненти
[10]. Тому фазу $\varphi$ ар нелінійної поляризації $P^{\mathrm{NL}}=$ $P_{0}^{\mathrm{NL}} \exp \left(-i \varphi_{\mathrm{ap}}\right)$ середовища на антистоксовій частоті можна подати у вигляді

$$
\begin{aligned}
& \varphi_{\mathrm{ap}}=2 \varphi_{\mathrm{L}}-\varphi_{\mathrm{s}}=2\left(\omega_{\mathrm{L}} t-k_{\mathrm{L}} z-\delta \varphi_{\mathrm{L}}\right)- \\
& -\left(\omega_{\mathrm{s}} t-k_{\mathrm{s}} z-\delta \varphi_{\mathrm{L}}\right)=\omega_{\mathrm{a}} t-k_{\mathrm{ap} 0} z-\delta \varphi_{\mathrm{L}} .
\end{aligned}
$$

Проте необхідно враховувати, що між фокальною точкою та вихідною межею середовища також є зміна показника заломлення. Випромінені поляризацією хвилі на частоті $\omega$ змінюють свою фазу на деяку величину $\delta \varphi_{\omega}(t, z)$, яка залежить від координати випромінюючого джерела та часу. Аналогічно до того, як отримано $\delta \varphi_{\mathrm{L}}(t, z)$, для $\delta \varphi_{\omega}(t, z)$ у випадку $\theta=0$ можна записати:

$\delta \varphi_{\omega}(t, z)=\int_{z}^{L / 2} \Delta k_{\omega}(t, \zeta) d \zeta$

$\Delta k_{\omega}=\Gamma_{\mathrm{f}} \exp \left[-\left(\zeta-v_{\mathrm{fp}}\left(t-\frac{z-\zeta}{v_{\mathrm{ph}}}\right)\right)^{2} / b^{2}\right]$.

Відмінність полягає в тому, що замість групової швидкості $v_{\mathrm{g}}$ світла на частоті лазерного випромінювання, з якою рухався часовий фрагмент лазерного імпульсу, фігурує фазова швидкість $v_{\mathrm{ph}}(\omega)$ випромінених хвиль на частоті $\omega$ та змінені межі інтегрування. Вирази (11) враховують, що деякий фазовий фронт, який в момент $t$ вийшов $з$ точки $z$, буде в точці $\zeta$, яка розташована на шляху від $z$ до вихідної межі середовища 3 координатою $L / 2$, в момент $t^{\prime \prime}=$ $t+(\zeta-z) / v_{\mathrm{ph}}$. В цей момент координата фокальної точки становитиме $z^{\prime \prime}{ }_{\mathrm{f}}=v_{\mathrm{fp}} t^{\prime \prime}=v_{\mathrm{fp}}\left(t+(\zeta-z) / v_{\mathrm{ph}}\right)$. Відстань між вказаним фазовим фронтом і фокальною точкою буде $\zeta-z^{\prime \prime}{ }_{\mathrm{f}}=\zeta-v_{\mathrm{fp}}\left(t+(\zeta-z) / v_{\mathrm{ph}}\right)=$ $\zeta-v_{\mathrm{fp}}\left(t-(z-\zeta) / v_{\mathrm{ph}}\right)$ і вона визначає показник заломлення у точці $\zeta$.

Для джерел у фокальній точці, де амплітуда поляризації максимальна, фазова затримка $\delta \varphi_{\omega}$ становить:

$$
\left.\delta \varphi_{\omega}\right|_{t=\frac{z_{\mathrm{f}}}{v_{\mathrm{fp}}}}=\Gamma_{\mathrm{f}} \int_{z_{\mathrm{f}}}^{L / 2} \exp \left[-\frac{\left(\zeta-z_{\mathrm{f}}\right)^{2}}{b^{2}}\left(1-\frac{v_{\mathrm{fp}}}{v_{\mathrm{ph}}}\right)^{2}\right] d \zeta .
$$

Вираз (12) показує, що $\delta \varphi_{\omega}$ на відміну від $\delta \varphi_{\mathrm{L}}$ залежить від координати фокальної точки і має певну 
особливість для швидкостей $v_{\mathrm{fp}}=v_{\mathrm{ph}}$. Якщо досліджувати поведінку $\delta \varphi_{\omega}$ в області $v_{\mathrm{fp}} \approx v_{\mathrm{ph}}$, то можна використати інтерполяцію $\exp \left[-x^{2}\right] \approx 1-x^{2}$ і отримати аналітичний вираз для $\delta \varphi_{\omega}$ у фокальній точці:

$\delta \varphi_{\omega} \mid \begin{aligned} & t=z_{\mathrm{f}} / v_{\mathrm{fp}} \\ & v_{\mathrm{fp}} \approx v_{\mathrm{ph}}\end{aligned}=$

$=\Gamma_{\mathrm{f}}\left[\left(\frac{L}{2}-z_{\mathrm{f}}\right)-\frac{\left(\frac{L}{2}-z_{\mathrm{f}}\right)^{3}\left(1-\frac{v_{\mathrm{fp}}}{v_{\mathrm{ph}}}\right)^{2}}{3 b^{2}}\right]$.

За аналогічних припущень для похідних маємо

$$
\left.\frac{\partial\left(\delta \varphi_{\omega}\right)}{\partial t}\right|_{\substack{t=z_{\mathrm{f}} / v_{\mathrm{fp}} \\ v_{\mathrm{fp}} \approx v_{\mathrm{ph}}}}=\frac{\Gamma_{\mathrm{f}} v_{\mathrm{fp}}}{b^{2}}\left(\frac{L}{2}-z_{\mathrm{f}}\right)^{2}\left(1-\frac{v_{\mathrm{fp}}}{v_{\mathrm{ph}}}\right),
$$

$$
\begin{aligned}
& \left.\frac{\partial\left(\delta \varphi_{\omega}\right)}{\partial z}\right|_{\substack{t=z_{\mathrm{f}} / v_{\mathrm{fp}} \\
v_{\mathrm{fp}} \approx v_{\mathrm{ph}}}}= \\
& =-\Gamma_{\mathrm{f}}\left[1+\frac{v_{\mathrm{fp}}}{v_{\mathrm{ph}} b^{2}}\left(\frac{L}{2}-z_{\mathrm{f}}\right)^{2}\left(1-\frac{v_{\mathrm{fp}}}{v_{\mathrm{ph}}}\right)\right] .
\end{aligned}
$$

В околі фокальної точки $\left(z \approx z_{\mathrm{f}}\right)$, використовуючи перші похідні, лінійну апроксимацію та нехтуючи членами, пропорційними $\left(1-v_{\mathrm{fp}} / v_{\mathrm{ph}}\right)^{2}$, фазову затримку $\delta \varphi_{\omega}$ можна подати у вигляді

$\delta \varphi_{\omega}=\Gamma_{\mathrm{f}}\left[L / 2+\left(v_{\mathrm{fp}}(L / 2-z)^{2}\left(1-v_{\mathrm{fp}} / v_{\mathrm{ph}}\right) / b^{2}\right) t-\right.$

$\left.-\left(1+\frac{v_{\mathrm{fp}}}{v_{\mathrm{ph}}}(L / 2-z)^{2}\left(1-v_{\mathrm{fp}} / v_{\mathrm{ph}}\right) / b^{2}\right) z\right]$.

3 точністю до сталих членів фаза $\varphi$ ар нелінійної поляризації з урахуванням обох фазових затримок $\delta \varphi_{\mathrm{L}}$, $\delta \varphi_{\omega}$ і корекцією $k_{\mathrm{ap} 0} \rightarrow k_{\mathrm{ap} 0}+\Gamma_{\mathrm{f}}$ (збільшення модулів хвильових векторів $k_{\mathrm{L}}$ i $k_{\mathrm{S}}$ у фокальній точці внаслідок СФ, але без ФС) набуває вигляду

$$
\begin{aligned}
& \varphi_{\mathrm{ap}}=\omega_{\mathrm{a}} t-k_{\mathrm{ap} 0} z-\delta \varphi_{\mathrm{L}}-\delta \varphi_{\omega}= \\
& =\left(\omega_{\mathrm{a}}+\frac{\Gamma_{\mathrm{f}} v_{\mathrm{fp}}}{1-v_{\mathrm{fp}} / v_{\mathrm{g}}}-\Gamma_{\mathrm{f}} v_{\mathrm{fp}} \frac{(L / 2-z)^{2}\left(1-v_{\mathrm{fp}} / v_{\mathrm{ph}}\right)}{b^{2}}\right) t-
\end{aligned}
$$

$$
-\left(k_{\mathrm{ap} 0}+\frac{\Gamma_{\mathrm{f}}}{1-v_{\mathrm{fp}} / v_{\mathrm{g}}}-\Gamma_{\mathrm{f}} \frac{v_{\mathrm{fp}}}{v_{\mathrm{ph}}} \frac{(L / 2-z)^{2}\left(1-v_{\mathrm{fp}} / v_{\mathrm{ph}}\right)}{b^{2}}\right) z .
$$

Припустимо, що амплітуда $P_{0}^{\mathrm{NL}}$ поляризації досягає максимального значення у фокальній точці, а розподіл амплітуди є гаусовим із півшириною $b$ на рівні $e^{-1}$ по осі $z$ i півшириною $a_{\mathrm{f}}$ по $x$ та $y$. Тоді для амплітуди поляризації маємо

$P_{0}^{\mathrm{NL}}=P_{0, \max }^{\mathrm{NL}} \exp \left[-\frac{x^{2}+y^{2}}{a_{\mathrm{f}}^{2}}-\frac{\left(z-v_{\mathrm{fp}} t\right)^{2}}{b^{2}}\right]$.

Спад амплітуди поляризації за віссю $z$ на відстані від точки $z_{\mathrm{f}}$ дає змогу використовувати лінійну апроксимацію (17) для затримки фази, оскільки похибка у визначенні фази поляризації нівелюється їі малою амплітудою.

Підставляючи $P^{\mathrm{NL}}=P_{0}^{\mathrm{NL}} \exp \left(-i \varphi_{\mathrm{ap}}\right)$ в $(1)$, після аналітичного інтегрування по $t, x, y$ для кута $\theta=0$ отримуємо вираз, у якому необхідно виконати інтегрування по $z$ :

$$
W_{\omega \theta}(\theta=0)=\frac{\pi n \omega^{4} a_{\mathrm{f}}^{4} b^{2}}{4 v_{\mathrm{fp}}^{2} c^{3}} P_{0, \max }^{\mathrm{NL}}{ }^{2} \mid \int_{-L / 2}^{L / 2} d z \exp \left[-\frac{b^{2}}{4 v_{\mathrm{fp}}^{2}} \times\right.
$$

$\times\left(\omega-\omega_{\mathrm{a}}-\frac{\Gamma_{\mathrm{f}} v_{\mathrm{fp}}}{1-v_{\mathrm{fp}} / v_{\mathrm{g}}}+\frac{\Gamma_{\mathrm{f}} v_{\mathrm{fp}}}{b^{2}}\left(\frac{L}{2}-z\right)^{2}\left(1-\frac{v_{\mathrm{fp}}}{v_{\mathrm{ph}}}\right)\right)^{2}-$

$\left.-i\left(k-k_{\mathrm{ap} 0}-\frac{\omega-\omega_{\mathrm{a}}}{v_{\mathrm{fp}}}-\frac{\Gamma_{\mathrm{f}}}{b^{2}}\left(\frac{L}{2}-z\right)^{2}\left(1-\frac{v_{\mathrm{fp}}}{v_{\mathrm{ph}}}\right)^{2}\right) z\right]\left.\right|^{2}$.

Подальші розрахунки частотно-кутової густини енергї можна виконати лише чисельно.

Опис розсіювання $\mathrm{AK}$ з кутами $\theta \neq 0$ вимагає додаткових уточнень. Для цього повернемось до виразів (11). Нехай розсіяне конусне випромінювання в площині $\{x, z, y=0\}$, в якій розташована вхідна щілина реєструючого спектрографа, поширюється з точки $z$ під кутом $\theta$ (рис. 1 ).

Припустимо, що деякий фазовий фронт хвилі вийшов із точки $z$ у момент часу $t$. В точці $F$ (рис. 1 ) фазовий фронт набуває поздовжньої координати $\zeta$ i $є$ віддаленим від осі $\mathbf{z}$ на $\chi=(\zeta-z) \operatorname{tg} \theta$, а від точки $z$ на $\sqrt{(\zeta-z)^{2}+\chi^{2}}$. Тому в точку $\zeta$ 
фронт надходить за часу $t+\sqrt{(\zeta-z)^{2}+\chi^{2}} / v_{\mathrm{ph}}=$ $t+(\zeta-z) /\left(v_{\mathrm{ph}} \cos \theta\right)$. Фокальна точка в цей момент займе координату $v_{\mathrm{fp}}\left(t+(\zeta-z) /\left(v_{\mathrm{ph}} \cos \theta\right)\right)$. Відстань між фронтом і фокальною точкою становитиме $\zeta-v_{\mathrm{fp}}\left(t+(\zeta-z) /\left(v_{\mathrm{ph}} \cos \theta\right)\right)$ за віссю $\mathbf{z}$ i $(\zeta-z) \operatorname{tg} \theta$ за віссю х. Таким чином, збільшення модуля хвильового вектора в точці $F$ (рис. 1) набуває значення:

$$
\begin{aligned}
& \Delta k_{\omega}=\Gamma_{\mathrm{f}} \exp \left[-\left(\frac{(\zeta-z) \operatorname{tg} \theta}{a_{\mathrm{f}}}\right)^{2}-\right. \\
& \left.-\left(\frac{\zeta-v_{\mathrm{fp}}\left(t+\frac{\zeta-z}{v_{\mathrm{ph}} \cos \theta}\right)}{b}\right)^{2}\right],
\end{aligned}
$$

де $a_{\mathrm{f}}$ - радіус фокальної області на рівні $e^{-1}$ змін $\Delta n$ i $\Delta k_{\omega}$.

Для обчислення затримки $\delta \varphi_{\omega}$ фази величина $\Delta k_{\omega}$ інтегрується за $\zeta$ у межах $\{z-L / 2\}$. Використання виразу (20) без додаткових наближень суттєво ускладнює процедуру отримання наближеного аналітичного виразу $\delta \varphi_{\omega}$ для $\theta \neq 0$, аналогічного (16).

Прийнятним спрощенням є таке подання $\delta \varphi_{\omega}$ для джерел з максимальною амплітудою коливань у фокальній точці:

$\left.\delta \varphi_{\omega}\right|_{t=\frac{z_{\mathrm{f}}}{v_{\mathrm{fp}}}}=\Gamma_{\mathrm{f}} \int_{z_{\mathrm{f}}}^{L_{z \theta}} \exp \left[-\frac{\left(\zeta-z_{\mathrm{f}}\right)^{2}}{b^{2}}\left(1-\frac{v_{\mathrm{fp}}}{v_{\mathrm{ph}} \cos \theta}\right)^{2}\right] d \zeta$

де у порівнянні з (12) замінено $v_{\mathrm{ph}}$ на $v_{\mathrm{ph}} \cos \theta$ і верхню межу $L / 2$ інтегрування на мінімальне значення $L_{z \theta}=\operatorname{Min}\left[L / 2 ; \quad z+a_{\mathrm{f}} \sqrt{\pi} /(2 \sin \theta)\right]$ з двох вказаних величин.

Можливість використання (21) перевірялася чисельними розрахунками. 3 фізичної точки зору вираз $(21)$ є наслідком заміни гаусового розподілу $\Delta k_{\omega}$ за віссю $\mathbf{x}$ на ступінчастий розподіл у фокальній площині $z=z_{\mathrm{f}}$ :

$\Delta k_{\omega}\left(x, y=0-a_{\mathrm{f}}\right)=\Gamma_{\mathrm{f}}, \quad \Delta k_{\omega}\left(x, y>a_{\mathrm{f}}\right)=0$

зі збереженням результуючого значення $\left.\delta \varphi_{\omega}\right|_{t=z_{\mathrm{f}} / v_{\mathrm{fp}}}$ для хвиль, які поширюються 3 фокальної точки за співвідношення швидкостей $v_{\mathrm{fp}} / v_{\mathrm{ph}}$ в околі $v_{\mathrm{fp}} / v_{\mathrm{ph}} \approx 1$.

Вираз (21) ідентичний отриманому раніше виразу (12) після замін $L / 2 \rightarrow L_{z \theta}, v_{\mathrm{ph}} \rightarrow v_{\mathrm{ph}} \cos \theta$. Такі



Рис. 1. Поширення розсіяного випромінювання з точки $z$ до межі середовища

підстановки дають змогу подальшого використання отриманих результатів (16), (17) у випадку $\theta \neq 0$ i $v_{\mathrm{ph}} \approx v_{\mathrm{ph}}$.

Для опису частотно-кутової структури розсіяння AK важливим є врахування фази хвиль, утворюваних у межах всієї фокальної області. Обмежимося урахуванням змін $\Delta n$ у фокальній площині, де амплітуда нелінійної поляризації є максимальною. За такого наближення у попередніх виразах необхідно виконати заміну

$\Gamma_{\mathrm{f}} \rightarrow \Gamma_{\mathrm{f}} \exp \left(-\frac{x^{2}+y^{2}}{a_{\mathrm{f}}^{2}}\right)$

Крім цього, для кутів $\theta \neq 0$ в (1) маємо врахувати, що $\mathrm{kr}=\Delta k_{\perp} x+\Delta k_{\|} z$, де $\Delta k_{\perp}=k \sin \theta \mathrm{i}$ $\Delta k_{\|}=k \cos \theta-k_{\text {ар0 }}$. Після всіх уточнень, які вимагають подальшого чисельного інтегрування за $x$ та $y$, вираз для частотно-кутової густини енергії $W_{\omega \theta}$ набуває вигляду

$W_{\omega \theta}=\frac{n \omega^{4} b^{2} P_{0, \max }^{\mathrm{NL}}{ }^{2}}{8 \pi v_{\mathrm{fp}}^{2} c^{3}} \mid \int_{0}^{\infty} d x \int_{0}^{\infty} d y \int_{-L / 2}^{L / 2} \exp \left[-\frac{x^{2}+y^{2}}{a_{\mathrm{f}}^{2}}-\right.$

$-i k_{\perp} x-\frac{b^{2}}{4 v_{\mathrm{fp}}^{2}}\left(\omega-\omega_{\mathrm{a}}-\frac{\Gamma_{\mathrm{f}} v_{\mathrm{fp}}}{1-v_{\mathrm{fp}} / v_{\mathrm{g}}}+\frac{\Gamma_{\mathrm{f}} v_{\mathrm{fp}}}{b^{2}}\left(L_{z \theta}-z\right)^{2} \times\right.$

$\left.\times\left(1-\frac{v_{\mathrm{fp}}}{v_{\mathrm{ph}} \cos \theta}\right)\right)^{2}-i\left(\Delta k_{\|}-\frac{\omega-\omega_{\mathrm{a}}}{v_{\mathrm{fp}}}-\frac{\Gamma_{\mathrm{f}}}{b^{2}}\left(L_{z \theta}-z\right)^{2} \times\right.$

$\left.\left.\times\left(1-\frac{v_{\mathrm{fp}}}{v_{\mathrm{ph}} \cos \theta}\right)^{2}\right) z\right]\left.d z\right|^{2}$ 


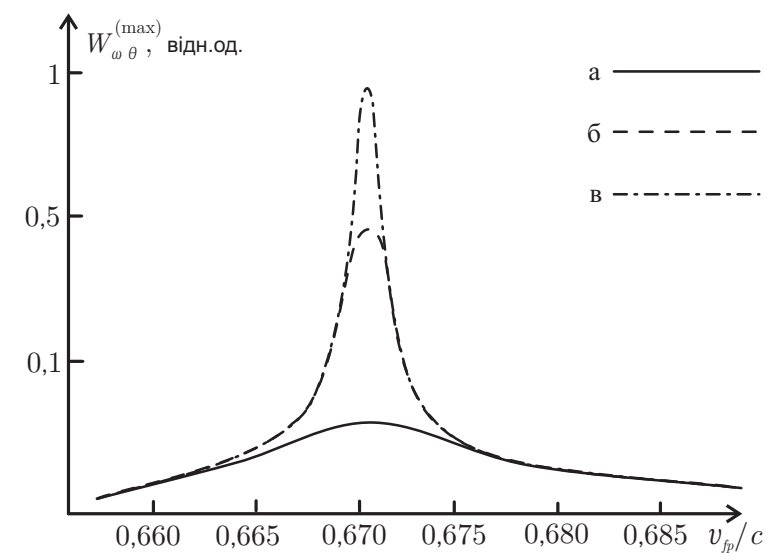

Рис. 2. Залежність пікової густини енергії випромінювання осьової антистоксової компоненти від швидкості руху фокальної області $v_{\mathrm{fp}}$ для $b=0,1$ см та різних значень $L: a-L=1 \mathrm{~cm}$; б-L $=2 \mathrm{~cm} ; в-L=3 \mathrm{~cm}$

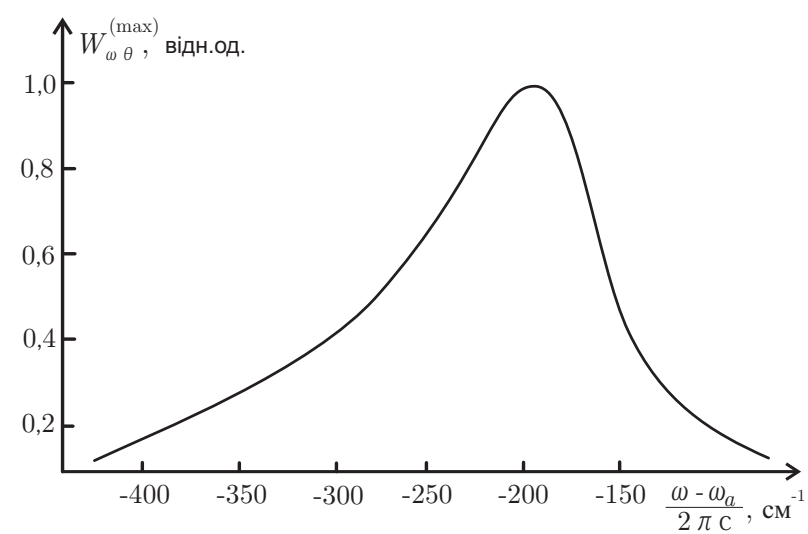

Рис. 3. Залежність пікової густини енергії випромінювання осьової антистоксової компоненти від частотного зсуву для $b=0,1 \mathrm{~cm}$ та $L=1 \mathrm{~cm}$

\section{3. Результати розрахунків}

Розрахунки виконували для ВКР у толуолі з комбінаційним зсувом AK $\left(\omega_{\mathrm{a}}-\omega_{\mathrm{L}}\right) / 2 \pi c=1004 \mathrm{~cm}^{-1}$. Використані дані про залежність $n(\omega)$ з роботи [11]. Вважалося, що $a_{\mathrm{f}}=5$ мкм [1]. Значення $\Gamma_{\mathrm{f}}$ вибиралось оптимальним $\left(\Gamma_{\mathrm{f}, \mathrm{opt}}\right)$, яке залежить від $v_{\mathrm{fp}}[12]$ :

$\Gamma_{\mathrm{f}, \mathrm{opt}} \approx \frac{\Delta k_{\mathrm{ap} 0}}{1-\left(1-v_{\mathrm{g}} / v_{\mathrm{ga}}\right) /\left(1-v_{\mathrm{g}} / v_{\mathrm{fp}}\right)}$,

де $v_{\mathrm{ga}}$ - групова швидкість світла на частоті $\omega_{\mathrm{a}}$. Для $\Gamma_{\mathrm{f}}=\Gamma_{\mathrm{f}, \mathrm{opt}}$ забезпечується максимальна ефективність генерації антистоксової компоненти. Для толуолу типове значення $\Gamma_{\mathrm{f}, \mathrm{opt}} \sim \Delta k_{\mathrm{ap} 0}=46 \mathrm{~cm}^{-1}$.

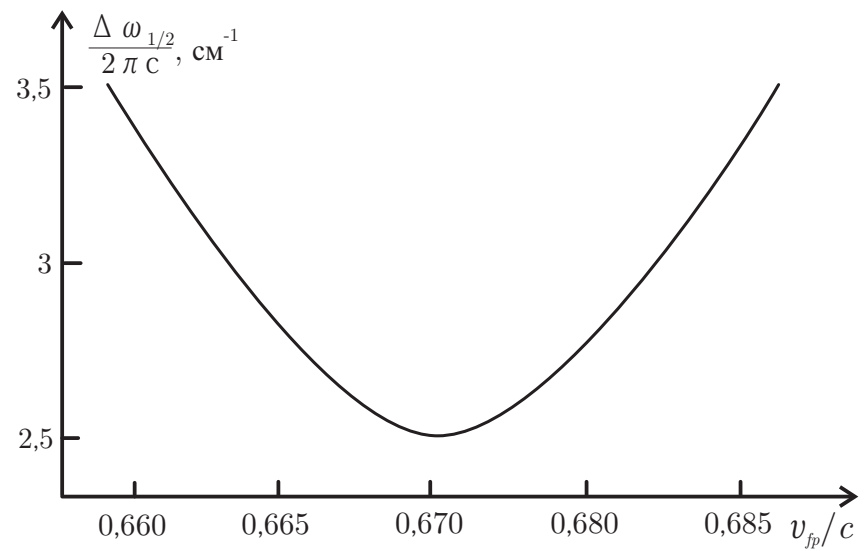

Рис. 4. Залежність ширини спектра випромінювання від швидкості руху фокальної області $(b=0,1$ см та $L=1 \mathrm{~cm})$

На рис. 2 подано залежність (19) пікової густини енергії $W_{\omega \theta}^{(\max )}$ осьового антистоксового випромінювання від швидкості фокальної області для $b=0,1$ см та різних значень $L$.

Швидкість фокальної області визначає частотне розташування піка енергії антистоксового випромінювання у спектрі. На рис. 3 показана залежність величини пікової густини енергії (у безрозмірних одиницях) від частотного зсуву $\left(\omega-\omega_{\mathrm{a}}\right) / 2 \pi c$ відносно комбінаційної антистоксової частоти.

Максимальне значення пікової густини енергії має спостерігатися на частоті випромінювання, фазова швидкість якого збігається зі швидкістю фокальної області: $v_{\mathrm{ph}}=v_{\mathrm{fp}}=0,67 c,\left(\omega-\omega_{\mathrm{a}}\right) / 2 \pi c=-197 \mathrm{~cm}^{-1}$.

На рис. 4 зображено залежність ширини спектра AK від швидкості руху фокальної області. Мінімальна ширина спектра реалізується у випадку $v_{\mathrm{fp}}=$ $0,67 c$ і становить близько $2,5 \mathrm{~cm}^{-1}$ за значень $L=1$ см та $b=0,1 \mathrm{~cm}$.

Для швидкості $v_{\mathrm{fp}}=0,67 c$ спектр осьової AK подано на рис. 5. Максимум енергії припадає на частоту $\left(\omega-\omega_{\mathrm{a}}\right) / 2 \pi c=-197 \mathrm{~cm}^{-1}$.

Наведені залежності отримано 3 використанням виразу (19) для осьового випромінювання. Повний частотно-кутовий розподіл $W_{\omega \theta}$ енергії випромінювання АК описується виразом (22). Для швидкості $v_{\mathrm{fp}}=0,67 c, L=1 \mathrm{~cm}, b=0,1 \mathrm{~cm}$ розташування розрахованої частотно-кутової смуги подано на рис. 6 (суцільна лінія). Для порівняння наведено експериментальну залежність (пунктирна лінія) з роботи [7]. Теоретична крива простягається до $-197 \mathrm{~cm}^{-1}$, у стоксовий бік, а експериментальна - до $-235 \mathrm{~cm}^{-1}$. За кутами маємо $\pm 86^{\prime}$ і $\pm 71^{\prime}$ відповідно. 


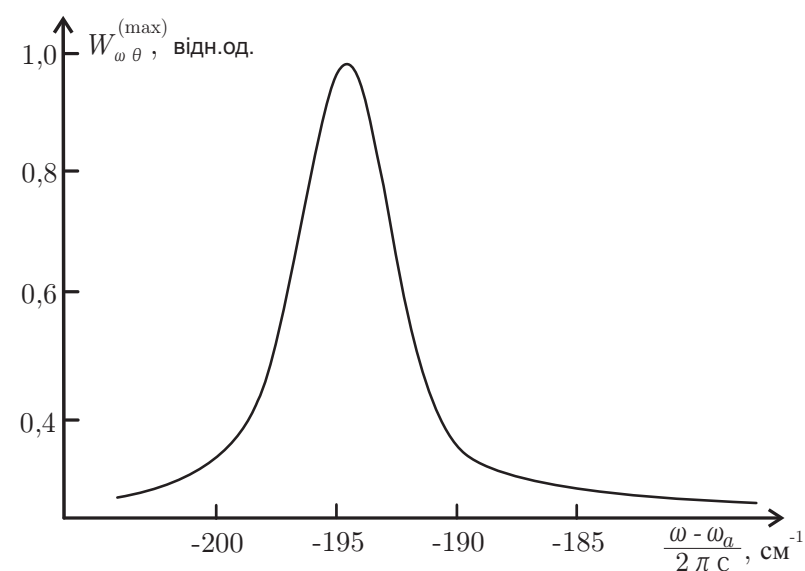

Рис. 5. Спектр випромінювання осьової антистоксової компоненти за швидкості $v_{\mathrm{fp}}=0,67 \mathrm{c}$

Кутові зрізи теоретичного розподілу $W_{\omega \theta}$ для деяких частотних зсувів показано на рис. 7 .

\section{4. Аналіз результатів та висновки}

Дослідження доводять, що частотно-кутова густина енергї АK, енергія фотонів якої перевищує енергію фотонів збуджуючого випромінювання, істотно залежить від швидкості руху фокальної точки СФ у ВКР-активних керрівських рідинах. За певних умов формується з високою ефективністю частотно-кутова індикатриса випромінювання черенковського типу: $\cos \theta(\omega) \approx v_{\mathrm{ph}}(\omega) / v_{\text {ap0 }}\left(\omega_{\mathrm{a}}\right)$. Зазначимо, що індикатриса та енергія власне черенковського випромінювання повністю описуються з використанням (1). Деталі опису містяться в роботі [13].

Важливими у формуванні частотно-кутової індикатриси АК є дві обставини. Насамперед, ФС збуджуючого лазерного випромінювання приводить до утворення антистоксової нелінійної поляризації середовища з частотою та фазовою швидкістю, зміщеними відносно комбінаційних. 3 урахуванням цього фактора спектр АK описано в [14]. За деяких швидкостей фокальної точки не менш істотною є і ФС самої АК на шляху від фокальної області до межі середовища. Оптична довжина цього шляху залежить від фазової швидкості АК та швидкості фокальної точки. Всяка зміна у часі оптичного шляху викликає доплер-ефект. Альтернативним та більш прийнятним є врахування змін оптичного шляху на основі ефекту ФС.

Пояснення взаємного впливу вказаних факторів можливе $з$ використанням діаграми Еренфеста [15] в осях з довжинами хвиль $\lambda$ (у середовищі) та фа-

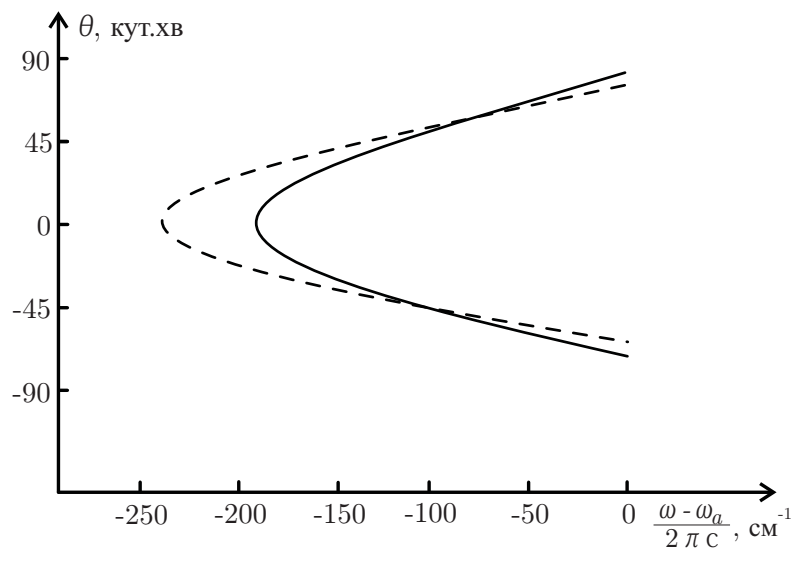

Рис. 6. Частотно-кутові смуги випромінювання антистоксової компоненти: суцільна лінія - теоретична $\left(v_{\mathrm{fp}}=0,67 \mathrm{c}, L=\right.$ 1 см, $b=0,1$ см); пунктирна лінія - експериментальна смуга

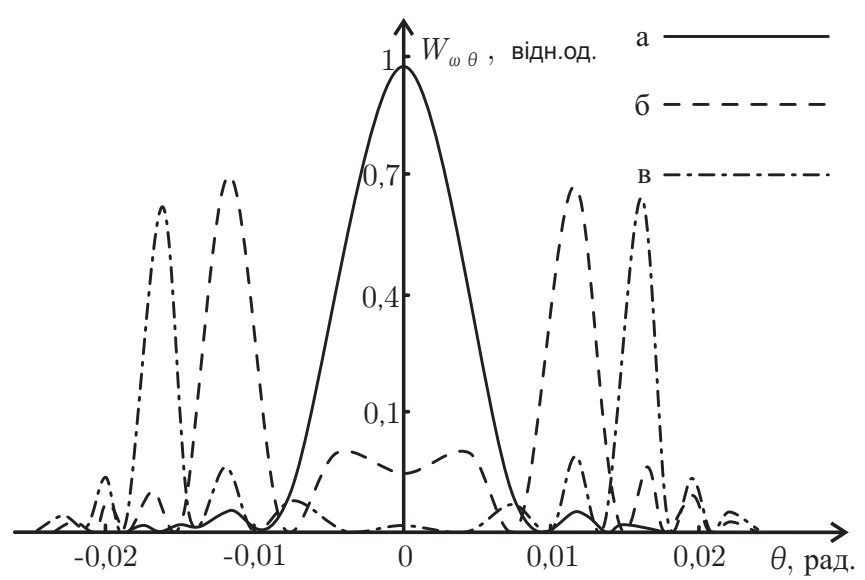

Рис. 7. Кутові залежності густини енергії випромінювання антистоксової компоненти у випадку $v_{\mathrm{fp}}=0,67 \mathrm{c}, L=1 \mathrm{~cm}$, $b=0,1$ см для частотних зсувів: $a--197 \mathrm{~cm}^{-1} ; \sigma--150 \mathrm{~cm}^{-1}$; в $-110 \mathrm{~cm}^{-1}$

зових швидкостей $v_{\mathrm{ph}}(\lambda)$ цих хвиль. Розгляд діаграми Еренфеста виявляє основні закономірності утворення широкосмугового випромінювання АK ВKР в СФ-середовищах. На рис. 8 діаграма побудована на прикладі толуолу, в якому $\omega_{\mathrm{a}} / 2 \pi c=1004 \mathrm{~cm}^{-1}$, для кута $\theta=0$ (осьове розсіяння).

Без урахування зміни показника заломлення нелінійна поляризація $\mathrm{AK}$ займає на діаграмі координати $P_{0}\left\{\lambda_{\text {ap } 0}, v_{\text {ap0 }}\right\}$, які становлять: $\lambda_{\text {ap0 }}=2 \pi / k_{\text {ap0 }}$, $v_{\text {ap0 }}=\omega_{\mathrm{a}} / k_{\mathrm{ap0}}$. Внаслідок дисперсії показника заломлення координати $P_{0}$ не належать дисперсійній кривій $D^{\prime} D^{\prime \prime}$ вільних електромагнітних хвиль у сере-






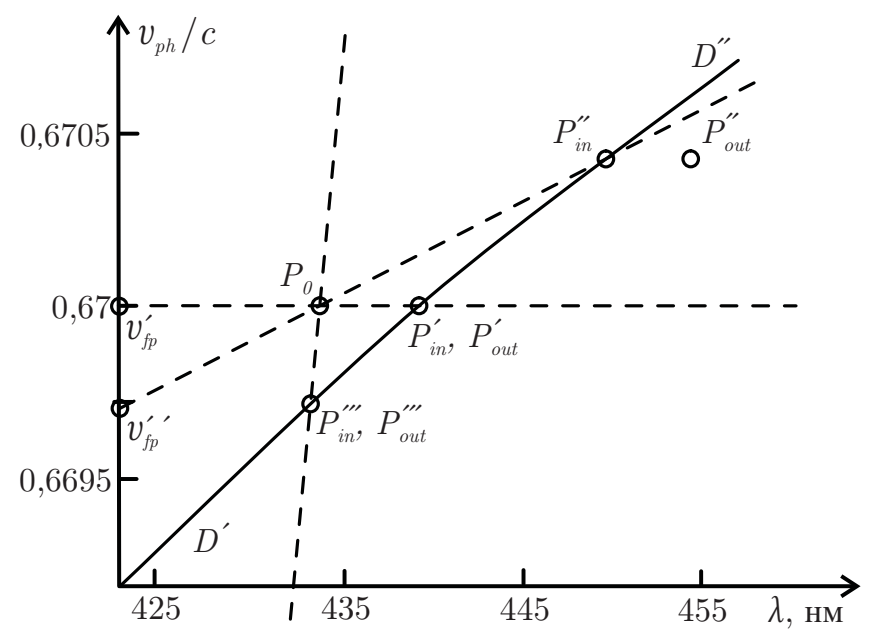

Рис. 8. Діаграма Еренфеста для толуолу $(\theta=0)$

вільних електромагнітних хвиль з такою ж довжиною хвилі, а тому є надсвітловою для даного середовища.

Часові зміни оптичного шляху лазерного випромінювання на шляху до фокальної точки СФ викликають ФС, а тому змінюють частоту, довжину хвилі та фазову швидкість утвореної нелінійної поляризації. 3 урахуванням ФС лазерного випромінювання на шляху до фокальної точки нелінійна поляризація АK набуває нових координат. Для вибраних на діаграмі швидкостей $v_{\mathrm{fp}}^{\prime}=v_{\mathrm{ap} 0}, v_{\mathrm{fp}}^{\prime \prime}=0,985 v_{\mathrm{ap} 0}, v_{\mathrm{fp}}^{\prime \prime \prime} \rightarrow 0$ координати поляризації в центрі фокальної точки мають значення $P_{\text {in }}^{\prime}, P_{\text {in }}^{\prime \prime}, P_{\text {in }}^{\prime \prime \prime}$. Вказані координати визначаються швидкістю фокальної точки та наведеним в ній показником заломлення, що пов'язаний з $\Gamma_{\mathrm{f}}$. Наприклад, для $P_{\text {in }}^{\prime}\left\{\lambda, v_{\text {ph }}\right\}$ з використанням $(9),(10)$ маємо

$P_{\text {in }}^{\prime}\left\{\begin{array}{l}2 \pi /\left(k_{\mathrm{ap} 0}+\Gamma_{\mathrm{f}} \frac{1}{1-v_{\mathrm{fp}}^{\prime} / v_{\mathrm{g}}}\right), \\ \left(\omega_{\mathrm{a}}+\Gamma_{\mathrm{f}} \frac{v_{\mathrm{fp}}^{\prime}}{1-v_{\mathrm{fp}}^{\prime} / v_{\mathrm{g}}}\right) /\left(k_{\mathrm{ap} 0}+\Gamma_{\mathrm{f}} \frac{1}{1-v_{\mathrm{fp}}^{\prime} / v_{\mathrm{g}}}\right)\end{array}\right\}$.

На діаграмі координати поляризацій $P_{\text {in }}^{\prime}, P_{\text {in }}^{\prime \prime}, P_{\text {in }}^{\prime \prime \prime}$ лежать на лініях $v_{\mathrm{fp}}^{\prime}-P_{0}, v_{\mathrm{fp}}^{\prime \prime}-P_{0}, v_{\mathrm{fp}}^{\prime \prime \prime}-P_{0}$ відповідно. Це зумовлено тим, що зміщення $\delta \omega_{\text {in }}=\omega_{\mathrm{Lf}}-\omega_{\mathrm{L}}=$ $\Gamma_{\mathrm{f}} v_{\mathrm{fp}} /\left(1-v_{\mathrm{fp}} / v_{\mathrm{g}}\right)$ частоти антистоксової поляризації i $\delta k_{\mathrm{in}}=k_{\mathrm{Lf}}-k_{\mathrm{L}}=\Gamma_{\mathrm{f}} /\left(1-v_{\mathrm{fp}} / v_{\mathrm{g}}\right)$ модуля хвильового вектора внаслідок ФС на шляху до фокальної точки пов'язані співвідношенням $\delta \omega_{\text {in }} / \delta k_{\text {in }}=v_{\text {fp }}$. Зміни $\Gamma_{\mathrm{f}}$ викликають зміщення координат поляризацій $P_{\text {in }}^{\prime}, P_{\text {in }}^{\prime \prime}, P_{\text {in }}^{\prime \prime \prime}$, але вони залишаються на відповідних лініях. Збільшення $\Gamma_{\mathrm{f}}$ віддаляе $P_{\mathrm{in}}^{\prime}, P_{\mathrm{in}}^{\prime \prime}, P_{\mathrm{in}}^{\prime \prime \prime}$ від $P_{0}$. За нульового $\Gamma_{\mathrm{f}}$ маємо $P_{\mathrm{in}}^{\prime}=P_{\mathrm{in}}^{\prime \prime}=P_{\mathrm{in}}^{\prime \prime \prime}=P_{0}$. Для оптимальних значень $\Gamma_{\mathrm{f}, \mathrm{opt}}$ координати $P_{\mathrm{in}}^{\prime}, P_{\mathrm{in}}^{\prime \prime}$, $P_{\text {in }}^{\prime \prime \prime}$ розташовуються на дисперсійній кривій $D^{\prime} D^{\prime \prime}$, як на рис. 8. У цьому випадку виконуються як умова амплітудно-фазового синхронізму [3] (швидкість фокальної точки, де амплітуда поляризації максимальна, збігається зі взаємною груповою швидкістю хвилі поляризації і вільної електромагнітної хвилі), так і умови фазового та групового синхронізмів. Якщо $\Gamma_{\mathrm{f}}\left(a_{\mathrm{f}}, \ldots\right) \neq \Gamma_{\mathrm{f}, \mathrm{opt}}$, то виконується лише умова амплітудно-фазового синхронізму. Особливості спостерігаються для швидкості $v_{\mathrm{fp}}^{\prime}$. Для цієї швидкості за довільних $\Gamma_{\mathrm{f}}$ виконується амплітудно-фазовий синхронізм та рівність фазових швидкостей поляризації з вільними електромагнітними хвилями.

Урахування ФС на виході з фокальної області змінює ситуацію, але залежно від швидкості $v_{\mathrm{fp}}$. Для швидкостей $v_{\mathrm{fp}}^{\prime}=v_{\mathrm{ap} 0}, v_{\mathrm{fp}}^{\prime \prime \prime} \rightarrow 0$ відповідні координати поляризацій $P_{\text {out }}^{\prime}, P_{\text {out }}^{\prime \prime \prime}$ на діаграмі залишаються незмінними. Для інших швидкостей $v_{\mathrm{fp}}$, а на рис. 8 це $v_{\mathrm{fp}}^{\prime \prime}=0,985 v_{\text {ap0 }}$, координати поляризації $P_{\text {out }}^{\prime \prime}$ залежать від $(L / 2-z)$, тобто від розташування $z=v_{\mathrm{fp}}^{\prime \prime} t$ фокальної точки і межі $L / 2$ середовища. Рух фокальної точки приводить до зміщення $P_{\text {out }}^{\prime \prime}$ приблизно паралельно осі $\lambda$. Це зумовлено тим, що зміщення частоти антистоксової поляризації

$\delta \omega_{\text {out }}=-\Gamma_{\mathrm{f}} v_{\mathrm{fp}}^{\prime \prime}\left(L / 2-z_{\mathrm{f}}\right)^{2}\left(1-v_{\mathrm{fp}}^{\prime \prime} / v_{\mathrm{ph}}\right) / b^{2}$

і модуля хвильового вектора

$\delta k_{\text {out }}=-\Gamma_{\mathrm{f}} v_{\mathrm{fp}}^{\prime \prime}\left(L / 2-z_{\mathrm{f}}\right)^{2}\left(1-v_{\mathrm{fp}}^{\prime \prime} / v_{\mathrm{ph}}\right) /\left(v_{\mathrm{ph}} b^{2}\right)$

внаслідок ФС на шляху від фокальної точки до межі середовища пов'язані співвідношенням $\delta \omega_{\text {out }} / \delta k_{\text {out }}=$ $v_{\text {ph }}$. На рис. 8 координати $P_{\text {out }}^{\prime \prime}$ нанесені для $L=$ $2,5 \mathrm{~cm}, b=0,25 \mathrm{mм}$, і оптимального значення $\Gamma_{\mathrm{f}}=$ $27,5 \mathrm{~cm}^{-1}$.

Зауважимо, в дійсності частота та модуль хвильового вектора нелінійної поляризація у фокальній точці не залежить від ФС вільних електромагнітних хвиль на шляху до межі середовища. Подана інтерпретація грунтується на розгляді спостережуваних властивостей поляризації на виході з середовища. Альтернативний опис полягає в урахуванні тих самих змін $\delta \omega_{\text {out }}, \delta k_{\text {out }}$ для вільних електромагнітних хвиль, але з протилежним знаком, тобто помноженими на "-". У будь-якому випадку маємо зміщення за віссю $\lambda$ на діаграмі (рис. 8) для $P_{\text {out }}^{\prime \prime}$.

Зміщення $P_{\text {out }}^{\prime \prime}$ за зміни розташування фокальної точки унеможливлюють ефективну ап-конверсію в AK та формування виражених піків частотно-кутової густини енергії $W_{\omega \theta}$. У цьому випадку не забезпечується фазове узгодження електромагнітних хвиль в 
площині реєстрації з різних ділянок траси фокальної точки. Для $v_{\mathrm{fp}}^{\prime \prime}$ не виконується ні амплітудно-фазовий синхронізм, ні умови фазового та групового синхронізмів на всьому шляху фокальної точки СФ.

$\mathrm{y}$ діапазоні, де швидкість $v_{\mathrm{fp}} \in$ близькою до фазової швидкості світла у середовищі, спостерігається чіткий максимум, який реалізується для швидкості $v_{\mathrm{fp}}^{\prime}=v_{\text {ap0 }}$ фокальної точки, рівній фазовій швидкості світла на частоті нелінійної поляризації у фокальній точці і фазовій швидкості самої поляризації.

У цьому випадку ФС лазерного випромінювання, яке попадає у фокальну точку, зміщує частоту нелінійної поляризації, але не впливає на їі фазову швидкість - фазова швидкість поляризації залишається такою ж, як і за відсутності СФ. 3 іншого боку, ФС випромінювання AK на виході з фокальної області не впливає ні на частоту, ні на фазову швидкість випромінювання.

Максимальна густина енергії осьового випромінювання AK припадає на частоту, яка визначається умовою, подібною до умови виникнення черенковського випромінювання: рівність фазової швидкості електромагнітної хвилі на частоті $\omega$ і фазової швидкості поляризації на антистоксовій комбінаційній частоті $\omega_{\mathrm{a}}$. Для толуолу зміщення частоти становить $\left(\omega(\theta=0)-\omega_{\mathrm{a}}\right) / 2 \pi c=-197 \mathrm{~cm}^{-1}$.

Для кутів $\theta \neq 0$ у випадку $v_{\mathrm{fp}}=v_{\mathrm{ap0}}$ частотнокутові смуги AK описуються співвідношенням

$\cos \theta(\omega) \approx v_{\mathrm{ph}}(\omega) / v_{\mathrm{ap} 0}$

яке у наближенні $\cos \theta \approx 1-\theta^{2} / 2$ дає параболи:

$\omega(\theta)-\omega_{\mathrm{a}} \approx\left(\omega(\theta=0)-\omega_{\mathrm{a}}\right)\left(1-\theta^{2} / \theta^{2}\left(\omega_{\mathrm{a}}\right)\right)$.

За вказаного співвідношення виконується амплітудно-фазовий синхронізм для довільних змін показника заломлення у фокальній області. Для оптимальних значень $\Gamma_{\mathrm{f}, \mathrm{opt}}(x, y, z)$ приросту $\Delta k_{\mathrm{L}}$ забезпечується рівність проекцій хвильових векторів поляризації та хвилі AK на поздовжню вісь, що є важливим в умовах поперечної обмеженості області існування нелінійної поляризації за СФ.

Теоретичні результати узгоджуються 3 експериментальними даними. Наявність відмінностей обговорювалася в [7].

Коротко резюмуючи, визначимо можливість аналогій між індикатрисами АK ВКР в умовах СФ і черенковським випромінюванням.

Частотно-кутова густина енергії обох процесів описується (1) і вони відбуваються за суттєвої поперечної обмеженості області існування поляризації.
Для ефекту Вавілова-Черенкова джерелом випромінювання є поляризація (об'ємна густина дипольного моменту), яка зумовлена зміною розташування вільного електрона із зарядом $q$ зі швидкістю $v_{q}$. Поляризація середовища за опису ефекту Вавілова-Черенкова не враховується. Внаслідок руху електрона спектральна компонента поляризації $P_{\omega}=\int_{-\infty}^{\infty} P(t, \mathbf{r}) \exp [i(\omega t)] d t$ з частотою $\omega$ має на осі $z$ модуль хвильового вектора $\omega / v_{q}$ та фазову швидкість $\omega /\left(\omega / v_{q}\right)=v_{q}$, оскільки [13]:

$P_{\omega}(x=0, y=0)=\frac{i q}{2 \pi \omega} \exp \left(\frac{i \omega z}{v_{q}}\right)$.

Джерелом випромінювання АK є нелінійна поляризація середовища у фокальній області. У випадку $v_{\mathrm{fp}}=v_{\mathrm{ap} 0}=\omega_{\mathrm{a}} / k_{\mathrm{ap} 0}$ спектральні компоненти спостережуваної поляризації AK з частотою $\omega$ у фокальній області описуються виразом

$P_{\omega} \sim \exp \left[-\frac{b^{2}}{4 v_{\mathrm{fp}}^{2}}\left(\omega-\omega_{\mathrm{a}}-\frac{\Gamma_{\mathrm{f}} v_{\mathrm{fp}}}{1-v_{\mathrm{fp}} / v_{\mathrm{g}}}\right)^{2}\right] \times$

$\times \exp \left[i\left(\left(\omega-\omega_{\mathrm{a}}\right) / v_{\mathrm{fp}}+k_{\mathrm{ap} 0}\right) z\right]$.

Цей вираз показує, що модуль хвильового вектора спектральних компонент поляризації становить $\left(\omega-\omega_{\mathrm{a}}\right) / v_{\mathrm{fp}}+k_{\mathrm{ap} 0}=\omega / v_{\mathrm{ap} 0}$, а їх фазова швидкість $v_{\text {ap0 }}$.

Тому за суттєвої поперечної обмеженості області існування поляризації для АK ВKР

$\cos \theta(\omega)=v_{\mathrm{ph}}(\omega) / v_{\mathrm{ap} 0}$

а для черенковського випромінювання

$\cos \theta(\omega)=v_{\mathrm{ph}}(\omega) / v_{q}$

1. И.Р. Шен, Принципы нелинейной оптики (Наука, Москва, 1989), с. 560.

2. А.И. Иванисик, В.И. Малый, Г.В. Понежа, Оптика и спектроскопия 80, 212 (1996).

3. А.І. Иванисик, Г.В. Понежа, Оптика и спектроскопия 90, 699 (2001).

4. С.О. Дудка, А.І. Іванісік, А.В. Конопатський, П.А. Коротков, Укр. фіз. журнал 51, 142 (2006).

5. В.Л. Гинзбург, Успехи физических наук 171, 1097 (2001).

6. А.І. Іванісік, А.В. Конопатський, Вісник Київського університету. Сер: фіз.-мат. науки 1, 244 (2007). 
7. А.И. Иванисик, В.И. Малый, Г.В. Понежа, Оптика и спектроскопия 82, 447 (1997).

8. В.Н. Луговой, А.М. Прохоров, ЖЭТФ 69, 84 (1975).

9. I. Blonskyi, V. Kadan, I. Dmitruk, and P. Korenyuk, Appl. Phys. B 104, 951 (2011).

10. А.П. Сухоруков, Нелинейные волновые взаимодействия в оптике и радиофизике (Наука, Москва, 1988), c. 232 .

11. А.И. Иванисик, В.И. Малый, Г.В. Понежа, Деп. в УкрНИИНТИ 615-Uk85, 7 (1985).

12. А.І. Іванісік, А.В. Конопатський, Вісник Київського університету. Сер: фіз.-мат. науки 3, 331 (2006).

13. O.Iu. Isaienko and A.I. Ivanisik, Proc. of XI International Young Scientists' Conference on Applied Physics (T. Shevchenko Nat. Univ. of Kyiv, Kyiv, 2011), c. 19.

14. О.Ю. Ісаєнко, А.І. Іванісік, Вісник Київського національного університету імені Тараса Шевченка. Сер: фіз.-мат. науки 4, 221 (2010).

15. Д.В. Сивухин, Оптика (Гл. ред. физ.-мат. лит., Москва, 1985), с. 752 .

Одержано 08.06.12

\section{ФАЗОМОДУЛИРОВАННОЕ ПАРАМЕТРИЧЕСКОЕ \\ АНТИСТОКСОВОЕ ВЫНУЖДЕННОЕ \\ КОМБИНАЦИОННОЕ РАССЕЯНИЕ \\ ЧЕРЕНКОВСКОГО ТИПА В \\ ОБЛАСТЯХ САМОФОКУСИРОВКИ \\ ВОЗБУЖДАЮЩЕГО ИЗЛУЧЕНИЯ}

А.И. Иванисик, А.Ю. Исаенко, П.А. Коротков, Г.В. Понежа

$\mathrm{P}$ е $з$ ю м е

Рассмотрено влияние скорости движения фокальной точки самофокусировки и фазовой самомодуляции на частотноугловые спектры излучения параметрической антистоксовой компоненты вынужденного комбинационного рассеяния. Учтена фазовая самомодуляция как возбуждающего, так и рассеянного антистоксового излучения. Объяснено образование протя- женных антистоксовых частотно-угловых полос. В случае совпадения скорости фокальной точки самофокусировки с фазовой скоростью нелинейной поляризации на антистоксовой комбинационной частоте и фазовой скоростью рассеянного осевого излучения, образуются интенсивные частотно-угловые полосы, которые описываются соотношениями, характерными для черенковского излучения. В частности, при возбуждении наносекундными лазерными импульсами в толуоле такие полосы достигают длины $\approx-200 \mathrm{~cm}^{-1}$ относительно комбинационной антистоксовой частоты.

\section{PHASE-MODULATED PARAMETRIC ANTI-STOKES STIMULATED RAMAN SCATTERING OF CHERENKOV-TYPE IN SELF-FOCUSING AREAS OF EXCITING RADIATION}

A.I. Ivanisik, O.Iu. Isaienko, P.A. Korotkov, G.V. Ponezha

${ }^{1}$ Taras Shevchenko National University of Kyiv,

Radiophysics Faculty

(2, Prosp. Build 4g, Academician Glushkov, Kyiv 03127, Ukraine; e-mail:aivan@univ.kiev.ua)

${ }^{2}$ National Academy of Statistics, Accounting and Auditing

(1, Pidhirna Str., Kyiv 04107, Ukraine)

$\mathrm{S} \mathrm{u} \mathrm{m} \mathrm{m} \mathrm{a} \mathrm{r} \mathrm{y}$

The influence of the speed of the focal point under self-modulation of the phase and self-focusing on the frequency-angular radiation spectra of a parametric stimulated Raman scattering (SRS) antiStokes component is considered. The phase self-modulation of both exciting and scattered anti-Stokes radiation is taken into consideration. The creation of broadened anti-Stokes frequencyangular bands is explained. The most intense frequency-angular bands, which are described by relations typical of the Cherenkov radiation, are generated when the speed of the self-focused focal point coincides with the phase velocity of a nonlinear polarization at the anti-Stokes Raman frequency and the phase velocity of a scattered axial radiation. In particular, under the excitation by nanosecond laser pulses, such bands in toluene reach shifts of $\approx-200 \mathrm{~cm}^{-1}$ relatively to the anti-Stokes Raman frequency. 